\title{
La presencia de Monseñor Romero en la Iglesia salvadoreña
}

\author{
Mons. Gregorio Rosa Chávez, \\ Obispo auxiliar de San Salvador.
}

Me piden hablar sobre la presencia de Monseñor Romero en la Iglesia salvadoreña. Es más fácil hacerlo en las circunstancias actuales, cuando parece que el país se está poniendo en estado de gracia con Monseñor Romero. ¿Quién iba a imaginar - para poner el hecho más sorprendente- que el periódico, en cuyas páginas se publicaron los peores ataques contra el pastor, durante su ministerio como arzobispo de San Salvador, iba a dedicarle seis páginas? Podríamos citar otros casos, como el de muchas personas sinceras que, llorando y de rodillas, piden perdón a Monseñor Romero, por haber dudado de él, o por haberlo calumniado y atacado.

A quienes nos visitan de otros países, quizá les parezca increíble que, en cuanto se conoció la noticia de su asesinato, muchas familias de los sectores ricos hicieron fiesta y reventaron cohetes. En esos días, mientras esperaba un taxi frente a la plaza de Las Américas, pude ver, en vehículos que bajaban de esos sectores, un sticker con la leyenda "Haga patria, mate un cura". Nunca pensaron que, veinticinco años más tarde, estaríamos rindiendo homenaje no sólo a San Romero de América, sino a San Romero del Mundo. En efecto, el planeta entero vibra en estos días con el testimonio martirial y profético del pastor santo que, como Jesús, pasó haciendo el bien... porque Dios estaba con el.

No quise preguntar a los organizadores en qué sentido había que enfocar el tema. Así me siento más libre para escoger el camino a seguir en esta exposición. Quisiera comenzar con una mirada retrospectiva a los tiempos anteriores a febrero de 1977, cuando Monseñor Romero empuñó el báculo pastoral, que le entregó Monseñor Luis Chávez y González; es decir, quisiera hablar brevemente del padre Romero, el sacerdote a quien conocí a mis catorce años, en la ciudad de San Miguel, y con quien tuve la gracia de trabajar durante un año, en mis tiempos de seminarista. En este período, encontramos algunos elementos que 
ayudan a comprender mejor al arzobispo Romero, profeta de fuego, y al Romero - como dice el conocido poema de Monseñor Casaldáliga - "pastor y mártir nuestro".

El padre Romero era un hombre de Dios, un pastor celoso, un incansable propagador de la devoción a la Virgen de la Paz, un hombre que se levantaba muy temprano y se acostaba después de media noche, siendo su última lectura los discursos y mensajes del Papa. No era de carácter fácil, pero cuando estaba ante un micrófono, se transformaba en otra persona. Después de la siesta, su primera actividad era dirigirse al templo para rezar el breviario, hacer la lectura espiritual y hablar a solas con el Señor, en el sagrario. Amigo de los placeres sencillos, se sentía muy a gusto con la gente pobre, y era feliz comiendo con los campesinos una tortilla con frijoles, bajo la sombra de su humilde rancho.

Pero no se puede hablar, hoy y aquí, de Monseñor Romero sin detener la mirada, aunque sea fugazmente, en el país en el cual le tocó servir. Y de nuevo, me gustaría destacar que no es lo mismo el país, visto desde la catedral de San Miguel, que El Salvador mirado desde el centro de poder económico, político y militar. No es lo mismo el país contemplado y experimentado desde un ambiente más bien sereno y amistoso, que visto desde la catedral de San Salvador, a donde llegaba el clamor del pueblo pobre, violentado en sus derechos fundamentales y sediento de justicia. Tocamos aquí el discutido tema de la conversión de Monseñor Romero. Estoy convencido que su respuesta, cuando le pregunté si se había convertido, es certera: "yo no diría que es una conversión; diría más bien que es una evolución".

El otro término del título de esta charla es "la Iglesia salvadoreña". Sabemos bien que, teológicamente, se prefiere hablar de la Iglesia en El Salvador o, según una frase consagrada, de la Iglesia que peregrina en El Salvador. Aquí es importante recordar que a Monseñor Romero le tocó vivir la Iglesia de los papas que él tanto admiró, en sus tiempos de estudiante en Roma: Pío XI y Pío XII. Vivió también con pasión la aventura de los años del concilio, pero sufrió intensamente cuando las enseñanzas conciliares se aplicaron a la realidad latinoamericana, en los documentos de Medellín.

Después de una verdadera crisis existencial, redescubrió Medellín como un acontecimiento salvífico, gracias sobre todo a Monseñor Eduardo Pironio, quien predicó un retiro a muchos obispos centroamericanos, en Antigua Guatemala. Por eso, al iniciar su ministerio como arzobispo, asumió con pasión la idea de Iglesia de la pascua, que describen los documentos de la Segunda conferencia general del episcopado latinoamericano. Esa fue la Iglesia que nos dejo como herencia.

Naturalmente, entre la Iglesia que soñó y construyó Monseñor Romero y la Iglesia que nosotros - los pastores y los demás fieles de este comienzo de milenio - construimos, hay bastante diferencia. Esta es la parte más delicada del 
tema, porque se presta a críticas estériles o a declaraciones románticas, que dejan las cosas como están, pero nos dan la sensación de que hemos hecho un acto admirable de profetismo. En otras palabras, tenemos un doble desafío. Por una parte, recuperar la pedagogía conciliar, que nos enseña a leer los signos de los tiempos; y por otra, tomar en serio la propuesta del papa Juan Pablo II para el nuevo milenio, que la Iglesia sea realmente "la casa y la escuela de la comunión, un lugar donde los pobres se sientan como en su casa" (Novo millennio Ineunte 43 y 50$)$.

\section{Monseñor Romero, más allá del mito}

Voy a comenzar mi exposición acercándome a la rica personalidad del cuarto arzobispo de San Salvador, tratando de no caer en la trampa del mito Romero, para intentar acercarme, con la mayor objetividad y honradez posible, al verdadero Monseñor Romero. Porque él no es ni un villano, ni un superhombre, sino un hombre y un cristiano con defectos y virtudes, que intentó estar siempre abierto a Dios y escuchar lo que el Espíritu dice a las iglesias.

Así lo afirma su vicario general, Monseñor Ricardo Urioste, presidente de la Fundación Romero:

Cuando después de su asesinato llegaban delegaciones de diversos países que admiraban mucho a Monseñor Romero, algunos preguntaban si era verdad que a Monseñor Romero lo habían manipulado un grupo de sacerdotes, o la izquierda, o algunos jesuitas. Y yo contestaba: "Sí, es verdad. Fue manipulado. Lo manipuló sólo Dios, que hizo con él lo que quiso".

Este es el verdadero Romero. La escucha atenta y dócil de la palabra de Dios lo moldeó y le llevó al martirio.

Pero junto a esta opinión podemos colocar muchas otras. Más aún, podemos afirmar que existen muchos mitos sobre Monseñor Romero. Cuando hablo del mito Romero, pienso en opiniones como la de un clérigo salvadoreño, que interpreta su nombramiento como fruto de una confabulación oscura. Este sacerdote formula su posición así:

En vista de que monseñor Luis Chávez y González y monseñor Arturo Rivera Damas fueron marginados por el Grupo de Reflexión Pastoral y por los nuevos jesuitas, éstos se dedicaron a buscar al futuro arzobispo de San Salvador. Monseñor Chávez iba a dimitir dentro de poco tiempo al cumplir los 75 años de edad. El candidato de ellos era monseñor Oscar Arnulfo Romero.

Por eso, "se inicia una campaña de desprestigio contra obispos candidatos a la sucesión y otra campaña de desprestigio contra el gobierno". ¿Y por qué Monseñor Romero? Nuestro autor responde: 
Con él, no se volvería atrás en la línea de pastoral encarnada en el pueblo, les permitiría instrumentalizar de lleno a la Iglesia y evitar todo enfrentamiento con la misma. La Iglesia católica era un instrumento de poder que debería colaborar a la causa de la revolución comunista.

Por su parte, la conocida publicación Carta a las iglesias (434, septiembre de 1999, p. 3-4), en un artículo que presenta a Monseñor Romero como un verdadero patriota, afirma:

En nuestro país se ha puesto de moda rendir tributo, como héroes nacionales, a figuras políticas o militares que, vistos con objetividad y honestidad, no son tales. Si para algo debieran servir las celebraciones del mes de septiembre es para traer a la memoria a aquellos salvadoreños que sí contribuyeron, con su trabajo y ejemplo, a que en El Salvador imperaran los valores de la paz, la justicia y la solidaridad. Y no cabe ninguna duda de que entre esos salvadoreños figuraría - debería figurar con todo derecho- Monseñor Oscar A. Romero, cuyo compromiso decidido con la construcción de un El Salvador en paz, justo y solidario sólo las mentes más obtusas se pueden negar a aceptar. Reconocer a Monseñor Romero como un héroe nacional, como un patriota, en el sentido pleno de la expresión, exige como paso previo desmitificar algunas de las visiones que, sobre su figura y trabajo pastoral, se han venido tejiendo.

¿Cuáles son esos mitos? El primero - ya lo vimos - es el que presenta a nuestro pastor y mártir como agitador profesional, al servicio de las organizaciones marxistas.

Todavía hay quienes piensan así; todavía hay quienes aceptan, sin el menor ánimo crítico, esta imagen equivocada - fraguada por los sectores más duros de la derecha salvadoreña, en los años setenta y ochenta.

Responde el autor del artículo que Monseñor Romero fue contundente en su crítica a la violencia como medio para resolver los problemas nacionales.

Y ello porque era consciente - como pocos en su tiempo- de que la violencia, al multiplicarse, se convierte en una "espiral de violencia", del cual los más perjudicados terminan siendo los que no poseen arma alguna para defenderse: los pobres.

\section{Otros ven en Monseñor Romero}

un hombre ingenuo y de buena fe, a quien se le forzó (por las vías del engaño y la manipulación) a que hiciera cosas y apoyara causas ajenas a su quehacer de pastor. Monseñor Romero era bueno - dicen-, pero tuvo malas influencias (entre otras, las de los jesuitas), los cuales se valieron de su humildad y debilidad de carácter. Por tanto, de lo de que se trata ahora es de rescatar a ese Monseñor Romero espiritual: es ese Monseñor Romero el que debe ser beatificado. 
Tampoco es válido, sigue afirmando Carta a las iglesias, el mito de Monsenor Romero manipulado.

Sin dejar de tener altibajos psicosomáticos $-i q u i e ́ n$, incluso con menos presiones, no los tiene?-, Monseñor Romero fue, en momentos cruciales, una personalidad de carácter, capaz de asumir con determinación, tras haber reflexionado detenidamente, decisiones difíciles y peligrosas. Un ser dócil y sin carácter no hubiera enfrentado a los militares y a los grupos de poder económico, habida cuenta de los mecanismos de seducción y chantaje de los que éstos quisieron valerse para sumarlo a sus filas, o al menos, para que dejara de ser tan molesto.

Por último, están aquellos que ven al arzobispo asesinado como un hombre con ideas claras, unívocas, que siempre sabía a qué atenerse o qué decisión tomar. Para éstos, Monseñor Romero es una especie de superhombre, incapaz de titubear o dudar: sus decisiones y opciones las tomó a partir de valoraciones frías y diáfanas de la realidad. Coherencia, frialdad, claridad y determinación: ¿no son éstas acaso virtudes que sólo los santos o los seres humanos extraordinarios pueden tener?

Ante esta visión también distorsionada, el autor recuerda que Monseñor Romero vivió en medio de dudas, equivocaciones y rectificaciones, pero

pudo medirle el pulso al país en aquellos años aciagos y tomar decisiones difíciles para él y para la Iglesia. Su diario personal no deja dudas al respecto: Monseñor Romero no siempre tuvo claridad plena acerca de lo que pasaba en el país o acerca de cuál era la mejor forma de responder ante las distintas coyunturas - sangrientas muchas de ellas- que se presentaban.

La conclusión vale la pena meditarla atentamente:

Fue un hombre abierto a lo que los demás podían decirle o enseñarle, sobre todo a lo que le podían decir los más pobres de El Salvador. Y en esto radicó lo extraordinario de él: en haber sido un ser humano cabal, un ser humano que con sus debilidades, titubeos, incertidumbres, pudo, tras buscar incansablemente los signos de los tiempos, estar a la altura de las exigencias que planteaba la realidad histórica salvadoreña, responder a lo que el país esperaba de su líder espiritual.

Pero, ¿se puede vivir sin mitos? Se ha anunciado para estos días la publicación de la biografía más documentada y desapasionada que se ha escrito hasta ahora. De esta forma, se pretende ir más allá del mito que se ha ido tejiendo sobre su persona para tratar de llegar al verdadero Oscar Romero (Roberto Moroso Della Rocca, Primero Dios. Vita di Óscar Romero, Milán, 2005).

Un historiador católico escribe al respecto: 
Romero, veinte años después de su muerte, sigue siendo un mito, como puede verse claramente en los sitios (de Internet) a él dedicados y por las reacciones emotivas, cuando se toca su aventura.

$Y$ a renglón seguido, añade:

El mito es un obstáculo para el trabajo del historiador. Obliga a proceder con gran paciencia, no sólo por el temor de ofender los sentimientos, sino también por la dificultad de hacer un buen discernimiento. A pesar de todo, también el mito es historia, aunque no siempre del personaje que se intenta investigar. El mito puede revelar la biografía del grupo que se representa (Andrea Riccardi, "Romero, entre el mito y la historia", en Oscar Romero, un obispo entre guerra fría y evolución, Madrid, 2003, p. 322).

Si queremos ir más allá del mito, no podemos olvidar que Monseñor Romero fue ante todo sacerdote. Dios quiso dejarlo claro al aceptar la ofrenda de la vida que hizo un mes antes, en su último retiro, precisamente a la hora del ofertorio. Quienes estuvimos cerca de él, podemos dar testimonio de su alma profundamente sacerdotal. El mismo lo confesó a un periodista que le preguntó sobre su vocación: "Si yo volviera a nacer, de nuevo escogería ser sacerdote".

Comprendo que este aspecto no sea relevante para quienes prefieren destacar el carácter profético de su personalidad, entendiendo profeta en un sentido a veces exclusivamente político y, por lo mismo, dejando a un lado su profundo significado bíblico. Pero, ¿qué es un profeta? Monseñor Romero nos deja en un diario esta bella descripción:

Desarrollé el tema presentando cómo la iniciativa siempre procede de Dios y como el profeta no es más que instrumento de Dios y cómo la sociedad acepta o rechaza a Dios en la persona del profeta (Diario, 8 de julio de 1979).

¿Cómo ir más allá del mito? El aporte más importante es el de Monseñor Arturo Rivera Damas, amigo personal y luego sucesor de Monseñor Romero. En el prólogo de la biografía escrita por Jesús Delgado, afirma:

Todavía no he quedado satisfecho de los libros que se han escrito sobre mi predecesor. Algunos autores, acertadamente presentan a Monseñor Romero como modelo de cristiano, que lleva hasta las últimas consecuencias la opción preferencial por el pobre, pero desatinan cuando presentan al pobre casi como sinónimo de revolucionario. Otros autores, en el afán polémico de defender a Romero de ataques y críticas, nos ofrecen un perfil de la grandeza de su persona y de su obra, pero al precio de ensombrecer o denigrar la personalidad de sus adversarios. 


\section{La herencia de Monseñor Romero: la Iglesia de la pascua}

Después de haber presentado al pastor, toca hablar de la Iglesia salvadoreña, o mejor dicho, de la Iglesia que nos dejó como preciosa herencia Monseñor Romero. Debo decir que no es otra sino la Iglesia de Jesús, la Iglesia del Vaticano II, encarnada en la realidad sangrante de nuestra historia. Por eso, tomaré como punto de partida el Concilio Vaticano II (1962-1965), que seguí con pasión, mientras realizaba mis estudios de teología en el seminario. Como sabemos, para acogerlo y asumirlo en la realidad del llamado continente de la esperanza, se celebró en Medellín (1968), la Segunda conferencia general del episcopado latinoamericano. Pero no podemos hablar del concilio sin recordar a su padre e inspirador, Juan XXIII. A él dedico mis primeras reflexiones.

Cuando estudiaba comunicación social, en Bélgica - hace unos veinticinco años- leí un libro de J. Gritti, que analizaba cómo la prensa acompañó el último tramo de la vida del Papa bueno. Su título era: Los últimos días de un gran hombre. Allí se demostraba que el párroco del mundo había conquistado el corazón de creyentes y no creyentes, de ricos y pobres, de hombres y mujeres de las más diversas ideologías: nunca, en la historia de la Iglesia, se había llorado tan sinceramente la muerte de un papa. En esa misma época, me encontré con el periodista Henri Fesquet, corresponsal del diario francés Le Monde, en el Vaticano, quien siguió día a día los trabajos del Concilio. Más tarde Fesquet escribió Les "fioretti" du bon pape Jean, una deliciosa selección de anécdotas al estilo de las Florecillas de San Francisco. Allí leemos historias como la siguiente:

La noche del día en que convocó a Concilio, el Papa cuenta que tenía dificultades para conciliar el sueño. Entonces se dijo: "Juan, ¿por qué no duermes? ¿Eres tú o el Espíritu Santo quien gobierna la Iglesia? Es el Espíritu Santo, ¿verdad? Entonces, duerme, Juan" (p. 43).

La plena confianza en Dios del Papa Roncalli sorprende. Como cuando afirma:

La idea del Concilio no ha madurado en mí como el fruto de una meditación prolongada, sino como la flor espontánea de una inesperada primavera (ibíd., p. 155).

Con la misma fe en la Providencia, hizo esta confidencia a un embajador acreditado ante la Santa Sede:

Del Concilio - dijo, acercándose a una ventana y haciendo el gesto de quererla abrir - espero un poco de aire fresco [...]. Hay que sacudir el polvo imperial que se ha acumulado sobre el trono de san Pedro, después de Constantino (ibíd., p. 157).

Solamente de esta manera la Iglesia será para la humanidad como una fuente de agua fresca: 
Hombres de todas las categorías vienen a mi pobre fuente. Mi función es dar agua a todos [...]. La Iglesia no es un museo de arqueología, sino la antigua fuente que da agua a las generaciones de hoy como la ha dado a las del pasado (ibíd., p. 162).

La pobreza de la Iglesia fue uno de los puntos centrales de su pontificado. Juan XXIII decía que la Iglesia quería ser la Iglesia de todos, pero sobre todo la Iglesia de los pobres. Su deseo era que los pobres se sintieran a gusto, en la Iglesia de Jesucristo, el pobre entre los pobres. Por eso, exhortó constantemente a los padres del concilio a tomar iniciativas en este sentido. En su discurso del 11 de septiembre de 1962, al abrir los trabajos conciliares, citó las palabras de Pedro: "No tengo oro ni plata, pero te doy lo que tengo: en nombre de Jesús de Nazaret, levántate y camina".

$\mathrm{Y}$ a continuación añadió:

Cierto, la Iglesia no ofrece riquezas caducas a los hombres de hoy, no promete una felicidad sólo terrena; los hace participantes de los bienes de la gracia divina [...]. Ella, finalmente, por medio de sus hijos, extiende por doquier la amplitud de la caridad cristiana, que, más que ninguna otra cosa, contribuye a extirpar las semillas de la discordia $y$, con mayor eficacia que con cualquier otro medio, fomenta la concordia, la justa paz y la unión fraternal de todos (16).

En el discurso de clausura de la primera sesión, el 8 de diciembre de 1962, habló con voz profética sobre los frutos que esperaba del concilio:

Será verdaderamente el "nuevo Pentecostés", que hará que florezca en la Iglesia su riqueza interior y su extensión hacia todos los campos de la actividad humana; será un nuevo paso adelante del reino de Cristo, en el mundo, un reafirmar de modo cada vez más alto y persuasivo la alegre nueva de la redención, el anuncio luminoso de la soberanía de Dios, de la fraternidad humana, de la caridad y de la paz prometida en la tierra a los hombres de buena voluntad, como respuesta al beneplácito celestial (ibíd., 22).

Esta fue la Iglesia que soñó Juan XXIII. Esta es la Iglesia que dibujó el concilio, en su luminoso magisterio: Iglesia-comunión, Iglesia-sacramento de la unión de los hombres con Dios y entre sí. O como enseña Juan Pablo II, la Iglesia que es "casa y escuela de comunión en la que los pobres se sientan como en su casa" (Novo Millennio Ineunte, 43 y 50).

Esta es también la Iglesia que todos nosotros estamos empeñados en construir: una Iglesia que comunique esperanza. No es fácil hablar hoy de esperanza, porque la realidad es abrumadoramente negativa y porque sólo los profetas pueden hablar con credibilidad de esperanza. En un mundo dominado por el materialismo, el individualismo, el hedonismo y el consumismo, hay otro evangelio, que se opone al mensaje liberador de Jesucristo. 
Les agradezco la oportunidad que ustedes me brindan, en esta Semana de teología, de dar testimonio acerca de la Iglesia de Monseñor Romero, el hombre que - retomando las palabras de Juan XXIII- escribió en el semanario de la diócesis de San Miguel, de la cual yo también provengo, en 1963, un bello homenaje a Juan XXIII y a su sucesor, Pablo VI:

Apenas caída la gloriosa bandera del Concilio con las manos muertas del Papa Juan XXIII... fue levantada en alto empuñada por las manos vigorosas del nuevo capitán del Reino de Dios. Su Santidad Pablo VI la hizo estandarte de su pontificado desde su primer mensaje al mundo cuando dijo: "El concilio Ecuménico Vaticano II será la obra principal a la que queremos consagrar todas las energías que el Señor nos ha dado para que la Iglesia Católica, que brilla en el mundo como el estandarte levantado sobre todas las naciones lejanas, pueda atraer hacia Ella a todos los hombres por la majestad de su organismo, por la juventud de su espíritu, por la renovación de sus estructuras, por la multiplicidad de sus fuerzas" (Chaparrastique, 12 de octubre de 1963).

En estos días de gracia, estamos reviviendo la experiencia extraordinaria de la Iglesia de Monseñor Oscar Arnulfo Romero y de su digno sucesor, Monseñor Arturo Rivera Damas. Una Iglesia que - como la que encarnó Juan XXIII - no se contentó con dar buenas noticias, sino que ella misma fue buena noticia. Así lo sienten millones de hombres y mujeres de todo el mundo, que esperan con impaciencia el momento en que culmine el proceso de canonización de Monseñor Romero, hombre de Dios abierto al Espíritu, que hace nuevas todas las cosas.

En este sentido, hace dos años, monseñor Ricardo Urioste escribía, en el semanario de nuestra arquidiócesis

En Monseñor Romero yo vi siempre a alguien guiado por el Espíritu y por eso "sorprendió" y "escandalizó". Fue un neto producto del Espíritu. Esa clase de santidad es extraña, no se entiende, casi no tiene puesto en la Iglesia (Orientación, 8 de junio de 2003, p. 11).

Pero está en buena compañía, porque Juan Pablo II nos enseñó a orar al Espíritu Santo no sólo como dulce huésped del alma, sino también como "memoria y profecía de la Iglesia que dirige la humanidad para que reconozca en Jesús de Nazaret el Señor de la gloria, el Salvador del mundo, la culminación de la historia" (Oración para el año del Espíritu Santo).

Sí, el Espíritu Santo es memoria y profecía de la Iglesia. Un grupo de sesenta sacerdotes de todo el país, que hicieron un curso sobre profetismo, nos lo recordó, en una carta muy respetuosa, enviada a los obispos de El Salvador y a sus compañeros presbíteros. Nos decían que nuestra Iglesia debe recuperar el profetismo que la caracterizó, en tiempos de Monseñor Romero.

En el plan pastoral de la arquidiócesis de San Salvador (1998-2003), hay un capítulo introductorio que recoge la historia de esa Iglesia particular, desde los 
tiempos del concilio hasta hoy. Lo sorprendente es la conclusión a la cual llegamos, sin sospecharlo: la Iglesia de San Salvador tomó en serio el concilio y, por eso, tuvo que pagar y pagó el precio de su fidelidad: el martirio.

Fue Monseñor Luis Chávez y González quien nos puso en estado de concilio:

Como miembro de la Comisión Central preparatoria del Vaticano II, Monseñor Chávez viajó siete veces a Roma. Al volver de la sexta reunión, en mayo de 1962, hizo público su compromiso con el Concilio, incluso antes de que éste comenzara sus trabajos. El vehemente deseo del arzobispo es "que toda su diócesis viva 'el estado de Concilio' en que se encuentra la Iglesia'... y que toda la diócesis esté unánimemente orando para que el Espíritu Santo, verdadero autor del Concilio, inspire a la santa Iglesia en su 'nueva Pascua y su nueva manifestación"' (Orientación, 758).

El venerado pastor cumplió su palabra y, por eso, siguió fielmente las indicaciones de los documentos de Medellín. Su sucesor, Monseñor Romero, siguió en la misma línea y aplicó también a la arquidiócesis el documento de Puebla (1979). El día que lo mataron, había leído, durante la homilía, el número 39 de Gaudium et Spes, donde el concilio afirma que, al final de los tiempos, serán restaurados los nuevos cielos y la nueva tierra, pero que "la espera de una tierra nueva no debe amortiguar, sino más bien avivar, la preocupación de perfeccionar esta tierra donde crece el cuerpo de la nueva familia humana".

Estamos, pues, en continuidad. En su carta pastoral La Iglesia de la pascua (abril de 1977), su presentación a la arquidiócesis, Monseñor Romero confiesa que toma el timón de la barca "con el respeto y delicadeza de quien siente que ha recibido una herencia de incalculable valor para continuar llevándola y cultivándola a través de nuevos y difíciles horizontes" (p. 5). En su carta, agradece a quienes compartieron "con múltiples demostraciones de solidaridad, el dolor y la esperanza que provocó el asesinato del inolvidable Padre Rutilio Grande y otros atentados contra la libertad de la Iglesia" (p. 8).

El nombre del Padre Rutilio trae a mi memoria el día que llamaron a Monseñor Romero de la nunciatura para reclamarle, porque había decidido que se celebrara en la arquidiócesis una sola misa para protestar por el asesinato de su gran amigo. Monseñor pidió al Padre Jon Sobrino y a mí que lo acompañáramos. Fue una reunión muy difícil y él salió descorazonado. Sin embargo, cuando llegó el día de la gran celebración, experimentó la respuesta de la multitud, sobre todo a la hora de la homilía. Uno de los concelebrantes cuenta que, al principio, Monseñor estaba muy nervioso, pero que todo cambió durante la homilía. La magia de su palabra fue envolviendo a la inmensa asamblea y él mismo se sintió acogido por ese pueblo sediento de justicia. "De repente" - escribe este sacerdote-, "Monseñor se hizo pueblo". La frase es bella y corresponde a la realidad. 
¿Qué sentimientos lo animan en su misión pastoral?

Represento a la Iglesia, la cual siempre está deseosa de dialogar con todos los hombres para comunicarles la verdad y la gracia que Dios le ha confiado a fin de orientar el mundo conforme a sus proyectos divinos" (ibíd., p. 8).

La afirmación central de la carta es:

la Iglesia no vive para sí misma, sino para llevar al mundo la verdad y la gracia de la pascua. He aquí - añade Monseñor Romero- la síntesis de esta carta que sólo quiere presentar, a la luz de esta "hora pascual", la identidad y la misión de la Iglesia y ofrecer con sinceridad su voluntad de diálogo con todos los hombres (ibid., p. 9).

A continuación sigue la descripción de la Iglesia que se proponía construir, en la geografía de su arquidiócesis:

Con emoción de pastor, me doy cuenta de que la riqueza espiritual de la pascua, la herencia máxima de la Iglesia, florece entre nosotros y que ya se está realizando aquí el deseo que los obispos expresaron en Medellín al hablar a los jóvenes: "que se presente, cada vez más nítido, en América Latina, el rostro de una Iglesia auténticamente pobre, misionera y pascual, desligada de todo poder temporal y audazmente comprometida en la liberación de todo el hombre y de todos los hombres" (Juventud, 15; los énfasis son suyos).

En la conclusión, formula el reto y los riesgos que esta hora difícil nos lanza:

Es el reto de una esperanza del mundo puesta en nuestra Iglesia. Seamos dignos de esta hora y sepamos dar razón de esa esperanza con nuestro testimonio de unidad, de comunión, de autenticidad cristiana y de un trabajo pastoral que, salvando con nitidez la supremacía de la misión religiosa de la Iglesia y de salvación en Jesucristo, tenga también muy en cuenta las dimensiones humanas del mensaje evangélico y las exigencias históricas de lo religioso y eterno (p. 22).

\section{Presencia de Monseñor Romero en la Iglesia salvadoreña}

¿Cómo se va perfilando la Iglesia de la pascua? Eso lo saben muy bien ustedes y, por eso, están ahora aquí, no sólo de El Salvador, sino de distintas partes del mundo. La pregunta es más bien ésta: ¿cómo vamos a conservar y enriquecer esta herencia, en este inicio de milenio, tan lleno de sombras y de desesperanza?

El jueves 24, expresé algunos pensamientos que me gustaría repetir aquí. Comencé preguntando quién nos convocaba junto a la tumba del pastor. Nos convocaba su presencia muda, en ese sepulcro nuevo; y también su cátedra, el ambón desde el cual tantas veces anunció la buena nueva del reino y denunció todo lo que se le oponía. Subrayé que su palabra sigue viva, según aquel famoso 
dicho suyo: "Mi voz desaparecerá, pero mi palabra, que es Cristo, quedará en quienes la hayan querido acoger". Luego, hice varias preguntas: ¿quiénes estamos aquí?, ¿por qué?, ¿en qué momento de la historia patria? La última pregunta era: ¿qué futuro deseamos construir?

Ahora deseo repetirlo en este auditorio. ¿Quiénes estamos aquí? Cristianos y no cristianos, salvadoreños y extranjeros, creyentes y no creyentes. Una cosa nos une, a pesar de las diferencias, creemos en la dignidad humana y creemos en el futuro. Les recordé, a este propósito, unas palabras de la homilía que Monseñor Romero pronunció dos semanas antes de su muerte:

Sin duda que me escucharán muchos políticos, muchos que sin fe en Dios están tratando de hacer una patria más justa, pero les diré: mis queridos hermanos ateos, mis queridos hermanos que no creen en Cristo, ni en la Iglesia: noble es su lucha, pero no es completa, déjense conducir por estos planes de Dios, por estos proyectos de liberación verdadera, incrusten su afán de justicia, en estos proyectos, que no terminan en la tierra, sino que le dan a los proyectos de la tierra la verdadera fuerza, el verdadero dinamismo, la verdadera proyección, la verdadera esperanza, la trascendencia.

¿Por qué estamos aquí? Nos une el amor a Monseñor Romero. Venimos en actitud de discípulos, a aprender de él como él aprendió de Jesús de Nazaret. Queremos recoger su memoria. Queremos conservar y hacer fructificar su herencia.

¿En qué momento de la historia patria estamos aquí? En un momento en el cual las sombras parecen ser más fuertes que la luz. En un momento de gran desaliento. Cuando los problemas parecen abrumarnos y las fuerzas sociales aparecen dispersas. Estamos aquí cuando se van cerrando los espacios de opinión, en algunos medios de comunicación social.

¿En qué futuro confiamos y cuál es nuestra utopía? Queremos un mundo en el cual reine la verdad, en el cual surja con fuerza la esperanza, en el cual brote por doquier la vida. En una palabra: queremos un nuevo país.

El mundo cambió dramáticamente desde aquel 11 de septiembre, cuando las torres gemelas de Nueva York fueron destruidas con un saldo de miles de muertes inocentes. Fue tan brutal la experiencia para el pueblo estadounidense que, desde entonces, se habla de antes y después del 11 de septiembre. Las encuestas muestran que, en ese gran país, reina el miedo y la incertidumbre. Parece que la esperanza ya no tiene espacio.

Creo que estarán de acuerdo conmigo que también nosotros usaremos un lenguaje parecido, al hablar de antes y después del vigésimoquinto aniversario del martirio de Monseñor Romero. Estamos viviendo la fiesta de la esperanza. La presencia de Monseñor Romero en la Iglesia salvadoreña se vuelve cada día más omnipresente. De nosotros depende que el sueño de Jesús vaya siendo carne 
y sangre, en el más lejano caserío, en los pequeños pueblos y en las grandes ciudades.

Dejemos a él la última palabra, sin ninguna glosa de mi parte. La tomo de su homilía del 9 de marzo de 1980:

Lo que nos quiere enseñar el evangelio es: ¿de qué sirve la vida por más pomposa que aparezca, si no produce frutos? ¡Higueras estériles! Y nos indica también la ternura y la paciencia de Dios esperando: tal vez el otro año, tal vez mañana. Es un llamamiento precioso de cuaresma para que revisemos nuestras vidas, a ver si de verdad hay frutos o somos higueras que inútilmente están ocupando la tierra, en el mundo.

Se necesitan hombres de buenas obras, se necesitan cristianos que sean luz del mundo, sal de la tierra. Hoy se necesita mucho el cristiano activo, crítico, que no acepta las condiciones sin analizarlas interna y profundamente. Ya no queremos masas de hombres con las cuales se ha jugado tanto tiempo, queremos hombres que como higueras productivas sepan decir sí a la justicia, no a la injusticia y sepan aprovechar el don precioso de la vida. Lo sepa aprovechar cualquiera que sea la situación. Queridos hermanos, el más humilde de los que estamos aquí, el más pequeño, el que se crea el más insignificante, es una vida que Dios mira con amor.

El plan de Dios lo conocemos en la realización de la historia de Israel. Él escogió ese pueblo, en medio de todas las naciones, para hacer un modelo de historia que, desde Cristo, desde su cruz, iba a ser la historia de salvación, en la historia de todos los pueblos. La historia de Israel se hace también, a través de la Iglesia, historia de nuestro pueblo salvadoreño. La historia de El Salvador es también vehículo del proyecto de Dios en la medida en que los salvadoreños hagamos nuestro ese proyecto de la historia de la salvación.

$\mathrm{Y}$ ahora, queridos hermanos, mi tercer y último pensamiento yo lo acomodo a nuestro querido pueblo, preguntando como tercera idea de esta homilía: ¿qué significa hoy para El Salvador, convertirse al Señor, por los caminos de Cristo? ¿Quién es el verdadero salvadoreño que se puede llamar hoy pueblo de Dios? El que camina muy adherido a Cristo, buscando esa Jerusalén celestial, trabajando por la tierra, pero no por sus propios proyectos, sino según el proyecto de Dios trascendente y que nos acerca al reino del Señor.

San Salvador, marzo de 2005. 